\title{
BMJ Open Lifestyle, socioeconomic status and healthcare seeking among women with gynaecological cancer alarm symptoms: a combined questionnaire-based and register-based population study
}

\author{
Kirubakaran Balasubramaniam, Sandra Elnegaard, Sanne Rasmussen, \\ Peter Fentz Haastrup, René dePont Christensen, Jens Søndergaard, \\ Dorte Ejg Jarbøl
}

To cite: Balasubramaniam $\mathrm{K}$, Elnegaard S, Rasmussen $\mathrm{S}$, et al. Lifestyle, socioeconomic status and healthcare seeking among women with gynaecological cancer alarm symptoms: a combined questionnairebased and register-based population study. BMJ Open 2018;8:e21815. doi:10.1136/ bmjopen-2018-021815

- Prepublication history for this paper is available online To view these files, please visit the journal online (http://dx.doi. org/10.1136/bmjopen-2018021815).

Received 18 January 2018 Revised 4 April 2018 Accepted 14 May 2018
Check for updates

Research Unit of General Practice, Department of Public Health, University of Southern Denmark, Odense, Denmark

Correspondence to Dr Kirubakaran Balasubramaniam; kiruba@health.sdu.dk

\section{ABSTRACT}

Objectives To determine the proportion of contacts to general practitioner (GP) with recent onset gynaecological cancer alarm symptoms (pelvic pain, postmenopausal bleeding, bleeding during intercourse or pain during intercourse) and to analyse the associations between lifestyle factors, socioeconomic status and GP contact for these symptoms.

Design Cross-sectional survey combined with data from national registers.

Setting The general Danish population.

Participants A total of 25866 non-pregnant women $\geq 20$ years completed the survey. Women reporting at least one of four gynaecological alarm symptoms within the preceding 6 months form the study base $(n=2957)$.

Results The proportion of women reporting GP contact ranged from $21.1 \%$ (pain during intercourse) to $32.6 \%$ (postmenopausal bleeding). Women aged 60+ years had higher odds of reporting GP contact for at least one of the four gynaecological cancer alarm symptoms compared with those aged $20-39$ years (OR 2.56, $95 \% \mathrm{Cl} 1.69$ to 3.89), and immigrants had higher odds of reporting GP contact for at least one of the symptoms $(0 \mathrm{R} 1.56,95 \% \mathrm{Cl}$ 1.13 to 2.15 ) compared with ethnic Danish individuals. Among those reporting postmenopausal bleeding and/or bleeding during intercourse, women in the age group $60+$ years had higher odds of reporting GP contact compared with those aged $20-39$ years (OR $2.79,95 \% \mathrm{Cl} 1.33$ to 5.87). A high educational level ( $>12$ years) was positively associated with reporting GP contact for postmenopausal bleeding and/or bleeding during intercourse compared with a low educational level ( $<10$ years) (OR $2.23,95 \% \mathrm{Cl}$ 1.19 to 4.19 ). No associations were found with lifestyle factors.

Conclusions Few women contacted their GP with recent onset gynaecological cancer alarm symptoms. Higher age, being immigrant and higher educational level increased the odds of GP contact. Future studies should explore the reasons for these findings as this may aid in prompting early diagnosis and thereby improve the prognosis of gynaecological cancer.

\section{Strengths and limitations of this study}

The population is large, which enables investigation of small subgroups.

- Socioeconomic data are obtained from national registers of high quality.

- Telephone interviews enabled additional responses from individuals who are usually rarely represented in surveys.

- General practitioner (GP) contacts are seen in relation to experienced symptoms, thus reflecting true actions rather than hypothetical situations.

- Data regarding GP contacts are self-reported and thus may be prone to bias.

\section{INTRODUCTION}

Several studies have shown that late-stage cancer diagnosis is associated with reduced survival. ${ }^{1-3}$ This is also the case for gynaecological cancer, and timely diagnosis and treatment are thus considered essential for prognosis.

For most patients, the diagnostic process is still initiated based on a symptom presentation, although some patients are diagnosed through screening programmes. ${ }^{4}$ The time period from the first symptom to diagnosis consists of several intervals, and each of these intervals contributes to the overall time spent in the diagnostic process. ${ }^{5}$ To reduce both the patient interval and the diagnostic interval, ${ }^{5}$ several countries have implemented referral guidelines and organisational changes. ${ }^{6} 7$ Most of these guidelines suggest that individuals presenting with symptoms indicative of cancer (alarm symptoms) should be urgently referred to specialised investigative trajectories. Some of the symptoms mentioned in guidelines are commonly occurring and often 
caused by benign conditions, ${ }^{8}$ which poses a clinical challenge due to the rather modest positive predictive values for cancer. On the other hand, most of the cancers must be detected among symptomatic individuals, ${ }^{4}$ which justifies the approach with fast-track investigations. Some of the symptoms prompt investigation as single symptoms, eg, postmenopausal bleeding, whereas others, eg, pain during intercourse, are rather considered as alarm symptoms in combination with other symptoms.

A prerequisite for the general practitioner (GP) to refer to specialised investigations is, however, that individuals contact the GP when experiencing symptoms. Evidently, not all symptom experiences lead to healthcare seeking, ${ }^{9-11}$ and several parameters might affect the decision to contact a GP with symptoms, such as socioeconomic status (SES), ${ }^{12}$ experience with illness ${ }^{13}$ and lifestyle factors (eg, smoking status, alcohol intake and body mass index (BMI) ${ }^{14-16}$ Specifically, studies show that sociodemographic factors are associated with prolonged time to diagnosis for a number of other cancers, while an unhealthy lifestyle is associated with longer intervals prior to diagnosis ${ }^{17-19}$ including gynaecological cancers. ${ }^{20}$ An enhanced understanding of the healthcare-seeking behaviour with gynaecological cancer alarm symptoms in different groups in the general population might improve policy interventions targeting early diagnosis of gynaecological cancer.

Therefore, the aims of this study were (1) to determine the proportion of women in the general population reporting recent onset of gynaecological cancer alarm symptoms with subsequent GP contact and (2) to analyse the associations between lifestyle factors, SES and contact to GP with gynaecological cancer alarm symptoms.

\section{METHODS}

The study was conducted as a nationwide combined questionnaire-based and register-based study. It is a part of a larger study, the Danish Symptom Cohort (DaSC), that investigates the prevalence of symptom experiences and healthcare-seeking behaviour in the general population. ${ }^{21}$ In Denmark, $98 \%$ of citizens are listed with a GP. The GPs have a gatekeeping role in the healthcare system and with the exception of very few situations, patients do not have direct access to secondary care nor to specialist care in primary care. The Danish healthcare system is tax funded and provides free medical care for all in both primary care and hospital setting. ${ }^{22}$

\section{Study subjects}

For the survey (DaSC), a random sample of 100000 adults aged 20 years or older was drawn from the Danish Civil Registration System (CRS), in which all Danish citizens are registered with a unique identification number. This identification number enables accurate linkage between national registers. The sampling procedure did not include individuals who had indicated in the CRS that they did not want to participate in research-related inquiries. Of the 100000 invited individuals, 51090 $(51.1 \%)$ were women, and only data for the women are included in this paper.

\section{The questionnaire}

The questionnaire was designed using the internet-based platform SurveyXact, and the invited individuals received a unique 12-digit login by postal letter. ${ }^{23}$ This login had to be entered on a secure webpage in order to access the questionnaire. In order to prevent exclusion of people with no internet access, the participants were offered to complete the survey by telephone interview. Questionnaire data were collected from June to December 2012.

The development of the questionnaire followed standardised and widely recognised procedures and was pilot tested in its entirety for content validity, relevance, acceptability and feasibility. The final version of the questionnaire was field tested on 500 individuals, randomly sampled from the CRS prior to the survey. The data quality, response rate, floor and ceiling effects, score ranges of single items and scores were assessed. Additional details about the design of the study and the data collection process are described elsewhere. ${ }^{21}$

A comprehensive questionnaire concerning the experience of 44 predefined specific and non-specific cancer alarm symptoms, as well as general and frequent symptoms, was developed. The alarm symptoms were selected based on a review of literature including national and international cancer referral guidelines. ${ }^{24-28}$ This study focuses on four symptoms (pelvic pain, postmenopausal bleeding, pain during intercourse and bleeding after intercourse), as these are mentioned in cancer referral guidelines regarding gynaecological cancer. ${ }^{25} 26$ The respondents were asked whether they had experienced one or more of the symptoms within the preceding 4 weeks, when they had experienced the first onset of the symptom(s), and whether they had contacted a GP about the symptom(s). The wording of the question regarding symptoms was: 'Have you experienced any of the following bodily sensations, symptoms or discomforts within the past 4 weeks? (Yes/no)'. A follow-up question for reported symptoms was phrased: 'When did you experience these for the first time? (Less than a month ago/1-3 months ago/3-6 months ago/More than 6 months ago)'. The question regarding contacting a GP was: 'Have you contacted your GP concerning the symptom(s) you have experienced within the preceding 4 weeks, through appointment, by telephone or email? (Yes/no)'. The questionnaire also included items about self-reported lifestyle factors, such as smoking habits and alcohol consumption. Respondents also reported their height and weight.

\section{Patient and public involvement}

Individuals from the general population only participated in the pilot testing and field testing of the questionnaire, and were otherwise not involved in the design of the study, research questions or other aspects of the 
survey, including recruitment and conduct of the study. The results of the study will be disseminated to the public by summaries in popular scientific magazines.

\section{Register data}

Information about SES and demographics was obtained from Statistics Denmark for each individual using the unique personal identification number in the CRS. Statistics Denmark is a governmental institution responsible for collecting and handling data from a number of social and administrative registers. ${ }^{29}$ Information about educational level, household income, labour market affiliation, cohabitation status and ethnicity was obtained via data

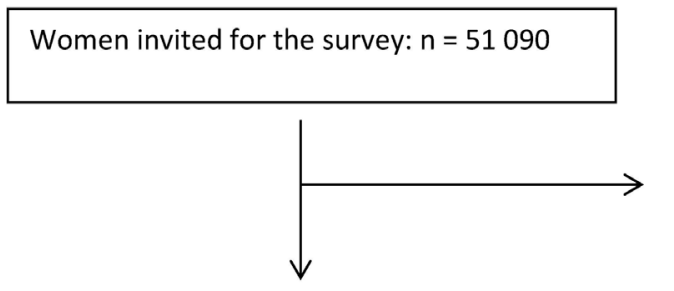

Eligible for the survey: $n=48606$ (95.1\%)

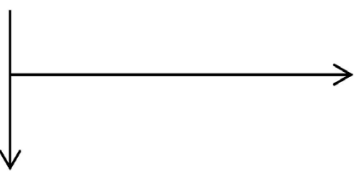

Respondents: $n=26466(54.5 \%)$

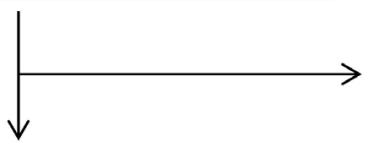

Non-pregnant women eligible for the study: $n=25866(53.2 \%)$

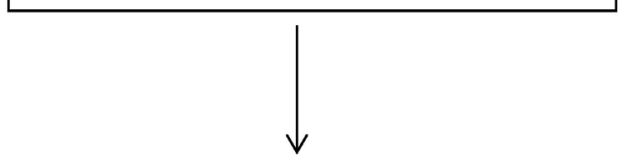

Fulfilling the criteria: Having experienced at least one gynaecological cancer alarm symptom* within the preceding four weeks and with onset less than six month ago: $\mathrm{n}=$ 2957 (11.4\%)

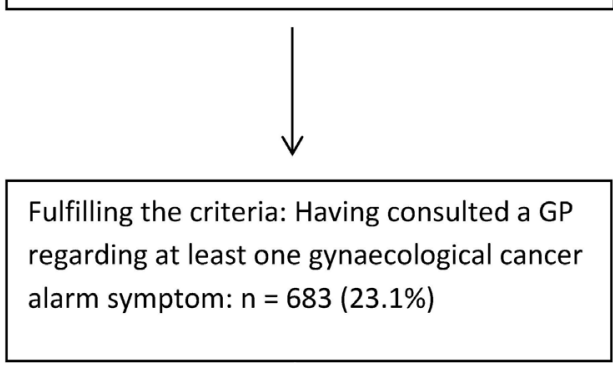

Figure 1 Study population. GP, general practitioner. linkage to this database for each respondent for the year 2011, the year before the survey.

\section{Statistical analysis}

In order to explore how recently onset symptoms were managed, symptoms with onset more than 6 months ago were excluded. As pregnant women may display a different healthcare-seeking behaviour compared with non-pregnant women, individuals who stated that they were pregnant within the preceding 6 months were excluded from the analyses (figure 1).

The proportions of women with recent onset of gynaecological symptoms and contact with a GP are presented

Excluded from the survey (dead, unknown address, severe illness including dementia, language problems and immigration abroad): $n=2484(4.9 \%)$

Non-respondents: $\mathrm{n}=22140(45.5 \%)$

Excluded due to pregnancy within the preceding 6 months: $n=600(2.3 \%)$

* Gynaecological cancer alarm symptoms:

- Pelvic pain

- Postmenopausal bleeding

- Bleeding during intercourse

- Pain during intercourse 
as percentages for each symptom. CIs were calculated using binomial distribution. Logistic regression models were used to calculate unadjusted and adjusted ORs for associations between GP contact with at least one of the four cancer alarm symptoms and each of the covariates. A subanalysis was performed for those reporting postmenopausal bleeding and/or bleeding during intercourse, as these symptoms from a clinical perspective are considered as especially alarming thus prompting fast investigation. The variables considered for analyses were age group, smoking status, alcohol consumption, BMI, educational level, income, labour market affiliation, cohabitation status and ethnicity. All these were categorical, and if they showed a significant association with GP contact in the crude logistic analyses, they were included in the subsequent logistic regression models.

Age was categorised as follows: $20-39,40-59$ or $60+$ years old. The BMI was calculated for each respondent who was then categorised as underweight (BMI $<18.5)$, normal weight $(18.5 \leq \mathrm{BMI}<25)$, overweight $(25 \leq \mathrm{BMI}<30)$ or obese (BMI $\geq 30$ ) according to WHO guidelines. ${ }^{30}$ Smoking status was categorised as never smokers, former smokers or current smokers. Alcohol consumption was categorised according to average intake (measured in units): $0,1-7$ units/week or $>8$ units/week. Education was categorised according to the highest attained educational level: low $(<10$ years, ie, primary and lower secondary school); middle (10-12 years, ie, vocational education and upper secondary school) or high (>12 years, ie, shortterm, medium-term or long-term higher education). ${ }^{31}$ Equivalence-weighted disposable income was categorised as low income (first quartile), middle income (second and third quartiles) or high income (fourth quartile). The equivalent disposable income comprises all income (wages, salaries, benefits and pensions) after taxation for the entire household and is adjusted for number of persons in the household. ${ }^{32}$ Labour market affiliation was categorised as currently working, pensioner or out of the workforce. Cohabitation status was categorised as cohabiting/married or single. Ethnicity was categorised as people of Danish origin, immigrants (individuals not born in Denmark by parents who holding Danish citizenships) or descendants of immigrants (individuals born in Denmark by parents who are neither born in Denmark nor holding Danish citizenships).

All statistical tests used a significance level of $p<0.05$. Data analyses were conducted using STATA statistical software V.13.1 (StataCorp).

\section{RESULTS}

A total of 26466 women completed the questionnaire, yielding a response rate of $54.5 \%$ for the women. The median age of the participants was 51 years (IQR 39-63) compared with 53 years (IQR 37-71) for non-participants. A total of $600(2.3 \%)$ stated that they had been pregnant within the preceding 6 months and were thus excluded from the analyses. A total of 2957 (11.4\%) of the remaining 25866 women reported at least one gynaecological cancer alarm symptom with onset within the preceding 6 months, figure 1 .

The descriptive data for the study population are shown in table 1 . The proportion of respondents reporting GP contact ranged from $21.1 \%$ for pain during intercourse to $32.6 \%$ for postmenopausal bleeding, table 2 .

Among individuals reporting at least one of the four cancer alarm symptoms, no significant association with GP contact was found for BMI, smoking status, alcohol consumption, household income, educational level or marital status. Thus, the variables included in the adjusted logistic model were age group, labour market affiliation and ethnicity. In the full model, we observed that women in the age group 60+ years had higher odds of reporting GP contact compared with the youngest age group (OR 2.56, 95\% CI 1.69 to 3.89). Likewise, immigrants had higher odds of reporting GP contact (OR 1.56, 95\% CI 1.13 to 2.15) compared with ethnic Danish individuals, table 3 .

In the subgroup analyses among women reporting postmenopausal bleeding and/or bleeding during intercourse, we found no associations with GP contact for smoking status, BMI, alcohol consumption, labour market affiliation, household income, ethnicity or marital status. Women aged $60+$ had higher odds of reporting GP contact compared with women in the age group 20-39 (OR 2.79, 95\% CI 1.33 to 5.87). Furthermore, those with a high educational level (>12 years) had higher odds of reporting GP contact compared with those with a low educational level ( $<10$ years) (OR $2.23,95 \%$ CI 1.19 to 4.19), table 4.

\section{DISCUSSION \\ Main findings}

In this nationwide study comprising 26466 women from the general Danish population, $23.1 \%$ of those reporting four specific gynaecological alarm symptoms with onset less than 6 months prior had contacted a GP with at least one of the symptoms. The proportion of GP contacts ranged from $21.1 \%$ (pain during intercourse) to $32.6 \%$ (postmenopausal bleeding).

Women in the oldest age group and immigrants had significantly higher odds of having contacted the GP when reporting at least one of the four symptoms. No associations were found with smoking status, BMI, alcohol consumption, labour market affiliation, household income, marital status or educational level. In the subgroup analysis of women reporting postmenopausal bleeding and/or bleeding during intercourse, higher age and a high educational level were associated with having contacted the GP. In this subgroup, no associations were found with labour market affiliation, household income, ethnicity, marital status or any lifestyle factors. 
Table 1 Descriptive data for the study population

\begin{tabular}{|c|c|c|}
\hline & $\begin{array}{l}\text { All } \\
\text { respondents, } \\
\text { n (\%) }\end{array}$ & $\begin{array}{l}\text { Symptomatic } \\
\text { women*, } \\
\text { n (\%) }\end{array}$ \\
\hline Total & 25866 (100.0) & 2957 (100.0) \\
\hline \multicolumn{3}{|l|}{ Age groups } \\
\hline 20-39 & $6151(23.8)$ & $1390(47.0)$ \\
\hline $40-59$ & $11078(42.8)$ & $1290(43.6)$ \\
\hline $60+$ & 8637 (33.4) & $277(9.4)$ \\
\hline \multicolumn{3}{|l|}{ BMI } \\
\hline $\begin{array}{l}\text { Underweight } \\
\text { (BMI <18.5) }\end{array}$ & $625(2.4)$ & $87(2.9)$ \\
\hline $\begin{array}{l}\text { Normal weight } \\
(18.5 \leq \mathrm{BMI}<25)\end{array}$ & $13552(52.4)$ & $1628(55.1)$ \\
\hline $\begin{array}{l}\text { Overweight } \\
(25 \leq \mathrm{BMI}<30)\end{array}$ & $6933(26.8)$ & $724(24.5)$ \\
\hline Obese (BMI $\geq 25)$ & 3571 (13.8) & $402(13.6)$ \\
\hline \multicolumn{3}{|l|}{ Smoking status } \\
\hline Never smokers & $12151(47.0)$ & $1384(46.8)$ \\
\hline Former smokers & 7571 (29.3) & $752(25.4)$ \\
\hline Current smokers & $5044(19.5)$ & $714(24.1)$ \\
\hline \multicolumn{3}{|l|}{ Alcohol consumption } \\
\hline 0 unit/week & 7738 (29.9) & $1056(35.7)$ \\
\hline 1-7 units/week & 12828 (49.6) & 1405 (47.5) \\
\hline$>8$ units/week & $5300(20.5)$ & $496(16.8)$ \\
\hline \multicolumn{3}{|l|}{ Labour market affiliation } \\
\hline Working & 17265 (66.7) & 2406 (81.4) \\
\hline Pensions & $5943(23.0)$ & $172(5.8)$ \\
\hline Out of workforce & 2636 (10.2) & $375(12.7)$ \\
\hline \multicolumn{3}{|l|}{$\begin{array}{l}\text { Equivalence-weighted } \\
\text { disposable income }\end{array}$} \\
\hline $\begin{array}{l}\text { Lowest group (first } \\
\text { quartile) }\end{array}$ & 4478 (17.3) & $659(22.3)$ \\
\hline $\begin{array}{l}\text { Middle group (second } \\
\text { and third quartile) }\end{array}$ & $13527(52.3)$ & $1602(54.2)$ \\
\hline $\begin{array}{l}\text { Highest group (fourth } \\
\text { quartile) }\end{array}$ & $7816(30.2)$ & $686(23.2)$ \\
\hline \multicolumn{3}{|l|}{ Ethnicity } \\
\hline Danish & 24150 (93.4) & 2728 (92.3) \\
\hline Immigration & $1555(6.0)$ & $196(6.6)$ \\
\hline $\begin{array}{l}\text { Descendants of } \\
\text { immigrants }\end{array}$ & $116(0.4)$ & $23(0.8)$ \\
\hline \multicolumn{3}{|l|}{ Marital status } \\
\hline Single & 7127 (27.6) & $839(28.4)$ \\
\hline Married/cohabiting & 18694 (72.3) & 2108 (71.3) \\
\hline \multicolumn{3}{|l|}{ Educational level } \\
\hline Low (<10years) & $5172(20.0)$ & $486(16.4)$ \\
\hline Middle (10-12 years) & $10819(41.8)$ & $1330(45.0)$ \\
\hline High (>12 years) & 9207 (35.6) & 1054 (35.6) \\
\hline
\end{tabular}

*Reporting at least one gynaecological cancer alarm symptom within the preceding 6 months.

$\mathrm{BMI}$, body mass index.
Table 2 Gynaecological cancer alarm symptoms within the preceding 6 months and self-reported contact to general practitioner (GP)

\begin{tabular}{lcc}
\hline Symptom & $\begin{array}{l}\text { Symptom } \\
\text { experiences, } \mathbf{n}\end{array}$ & $\begin{array}{l}\text { Contact to GP, } \\
\mathbf{n}(\%)\end{array}$ \\
\hline $\begin{array}{l}\text { Pelvic pain } \\
\begin{array}{l}\text { Postmenopausal } \\
\text { bleeding }\end{array}\end{array}$ & $\begin{array}{c}2184 \\
\text { Pain during }\end{array}$ & $62(22.3)$ \\
$\begin{array}{l}\text { intercourse } \\
\begin{array}{l}\text { Bleeding during } \\
\text { intercourse }\end{array}\end{array}$ & 867 & $183(21.1)$ \\
$\begin{array}{l}\text { At least one of the } \\
\text { above-mentioned } \\
\text { symptoms }\end{array}$ & 2957 & $90(25.9)$ \\
$\begin{array}{l}\text { Postmenopausal } \\
\text { bleeding and/or } \\
\text { bleeding during } \\
\text { intercourse }\end{array}$ & 523 & $683(23.1)$ \\
\hline
\end{tabular}

\section{Study strengths and limitations}

Strengths of this study include the large study sample (51 090 women) and the relatively high response rate (54.5\% among women). An overall responder analysis of the entire study cohort including both genders showed that respondents were more often cohabiting, had higher educational level, had higher income, were of Danish origin and more were affiliated with the workforce. ${ }^{11}$

In Denmark, detailed socioeconomic and demographic data on an individual level are available, based on administrative data and defined in Statistics Denmark. ${ }^{31} 32$ The quality of these data is in general high and there is a low risk of misclassification. ${ }^{29}$

Some of the symptoms mentioned in guidelines are frequently occurring in the general population, and mostly caused by benign conditions, for example, normal menstrual cycle. ${ }^{8}$ As both the symptoms ${ }^{33}$ and gynaecological cancers are age dependent, ${ }^{34}$ exploring the healthcare seeking for each symptom in different age groups would be of great value. However, some of the symptoms were somewhat rare and analysing these separately with regard to the explanatory variables would be in violation with Danish legislation and data protection regulations. In a previous study based on the same population cohort, increasing age was found to be significantly associated with healthcare seeking regardless of symptom type, supporting that our finding regarding age may be due to other factors than the individual symptoms alone. ${ }^{35}$

This study is based on self-reported symptoms within a time frame of 4 weeks with onset less than 6 months prior to questionnaire distribution and GP contacts regarding these symptoms. Even though the time spans are relatively short, some memory decay cannot be ruled out, which may result in under-reporting of 
Table 3 Crude ORs and adjusted ORs for associations between lifestyle factors, socioeconomic status and contact to GP with at least one of the four cancer alarm symptoms (symptom experiences $<6$ months)

\begin{tabular}{|c|c|c|c|c|c|c|}
\hline & \multicolumn{3}{|c|}{ Crude ORs } & \multicolumn{3}{|c|}{ Adjusted ORs* } \\
\hline & OR & $P$ values & $95 \% \mathrm{Cl}$ & OR & $P$ values & $95 \% \mathrm{Cl}$ \\
\hline \multicolumn{7}{|l|}{ Age group } \\
\hline 20-39 & 1.00 & - & 1.00 to 1.00 & 1.00 & - & 1.00 to 1.00 \\
\hline $40-59$ & 1.11 & 0.284 & 0.92 to 1.33 & 1.13 & 0.198 & 0.94 to 1.36 \\
\hline $60+$ & 1.91 & $<0.001$ & 1.45 to 2.53 & 2.56 & $<0.001$ & 1.69 to 3.89 \\
\hline \multicolumn{7}{|l|}{ Smoking status } \\
\hline Never smoker & 1.00 & - & 1.00 to 1.00 & & & \\
\hline Former smoker & 1.04 & 0.699 & 0.85 to 1.28 & & & \\
\hline Current smoker & 0.93 & 0.533 & 0.75 to 1.16 & & & \\
\hline \multicolumn{7}{|l|}{ BMI } \\
\hline Underweight & 1.00 & - & 1.00 to 1.00 & & & \\
\hline Normal weight & 1.43 & 0.209 & 0.82 to 2.48 & & & \\
\hline Overweight & 1.22 & 0.497 & 0.69 to 2.16 & & & \\
\hline Obese & 1.21 & 0.532 & 0.67 to 2.18 & & & \\
\hline \multicolumn{7}{|l|}{ Alcohol consumption } \\
\hline 0 & 1.00 & - & 1.00 to 1.00 & & & \\
\hline $1-7$ & 0.97 & 0.730 & 0.80 to 1.17 & & & \\
\hline$>8$ & 1.03 & 0.830 & 0.80 to 1.32 & & & \\
\hline \multicolumn{7}{|l|}{ Labour market affiliation } \\
\hline Working & 1.00 & - & 1.00 to 1.00 & 1.00 & - & 1.00 to 1.00 \\
\hline Pensions & 1.49 & 0.022 & 1.06 to 2.09 & 0.64 & 0.089 & 0.38 to 1.07 \\
\hline Out of workforce & 1.04 & 0.786 & 0.80 to 1.34 & 0.92 & 0.523 & 0.70 to 1.20 \\
\hline \multicolumn{7}{|l|}{$\begin{array}{l}\text { Equivalence-weighted disposable } \\
\text { income }\end{array}$} \\
\hline Low (first quartile) & 1.00 & - & 1.00 to 1.00 & & & \\
\hline Middle (second and third quartile) & 0.97 & 0.784 & 0.78 to 1.20 & & & \\
\hline High (fourth quartile) & 1.07 & 0.582 & 0.83 to 1.38 & & & \\
\hline \multicolumn{7}{|l|}{ Ethnicity } \\
\hline Danish & 1.00 & - & 1.00 to 1.00 & 1.00 & - & 1.00 to 1.00 \\
\hline Immigrants & 1.52 & 0.010 & 1.10 to 2.08 & 1.56 & 0.007 & 1.13 to 2.15 \\
\hline Descendants of immigrants & 0.95 & 0.927 & 0.35 to 2.58 & 1.06 & 0.913 & 0.39 to 2.87 \\
\hline \multicolumn{7}{|l|}{ Marital status } \\
\hline Single & 1.00 & - & 1.00 to 1.00 & & & \\
\hline Married/living together & 0.99 & 0.892 & 0.82 to 1.19 & & & \\
\hline \multicolumn{7}{|l|}{ Educational level } \\
\hline Low (<10years) & 1.00 & - & 1.00 to 1.00 & & & \\
\hline Middle (10-12 years) & 0.88 & 0.322 & 0.69 to 1.13 & & & \\
\hline High (>12 years) & 0.89 & 0.362 & 0.69 to 1.14 & & & \\
\hline
\end{tabular}

${ }^{*}$ Adjusted for age, labour market affiliation and ethnicity.

Bold denotes significant result with $p$-value $<0.05$.

$\mathrm{BMI}$, body mass index; GP, general practitioner.

both symptoms and GP contacts. On the other hand, some individuals may have felt that the alarm symptoms should have led to GP contact, which may have resulted in desirability bias. The time for GP contact was not specified as the intention was to obtain information on all GP contacts.

Furthermore, it is important to keep in mind that the lifestyle factors (alcohol consumption, smoking status 
Table 4 Crude ORs and adjusted ORs for associations between lifestyle factors, socioeconomic status and contact to GP with postmenopausal bleeding and/or bleeding during intercourse (symptom experiences $<6$ months)

\begin{tabular}{|c|c|c|c|c|c|c|}
\hline \multirow{4}{*}{ Age group } & \multicolumn{3}{|c|}{ Crude ORs } & \multirow{2}{*}{\multicolumn{3}{|c|}{ Adjusted ORs* }} \\
\hline & \multirow[t]{2}{*}{ OR } & \multirow[t]{2}{*}{$P$ values } & \multirow[t]{2}{*}{$95 \% \mathrm{Cl}$} & & & \\
\hline & & & & & & \\
\hline & 1.00 & - & 1.00 to 1.00 & 1.00 & - & $1.00-1.00$ \\
\hline $40-59$ & 1.32 & 0.189 & 0.87 to 1.98 & 1.35 & 0.166 & $0.88-2.05$ \\
\hline $60+$ & 2.75 & 0.005 & 1.36 to 5.56 & 2.79 & 0.007 & $1.33-5.87$ \\
\hline \multicolumn{7}{|l|}{ Smoking status } \\
\hline Never smoker & 1.00 & - & 1.00 to 1.00 & & & \\
\hline Former smoker & 1.30 & 0.271 & 0.82 to 2.07 & & & \\
\hline Current smoker & 0.95 & 0.843 & 0.59 to 1.54 & & & \\
\hline \multicolumn{7}{|l|}{ BMI } \\
\hline Underweight & 1.00 & - & 1.00 to 1.00 & & & \\
\hline Normal weight & 1.69 & 0.358 & 0.55 to 5.22 & & & \\
\hline Overweight & 1.38 & 0.592 & 0.43 to 4.42 & & & \\
\hline Obese & 1.82 & 0.335 & 0.54 to 6.14 & & & \\
\hline \multicolumn{7}{|l|}{ Alcohol consumption } \\
\hline 0 & 1.00 & - & 1.00 to 1.00 & 1.00 & - & $1.00-1.00$ \\
\hline $1-7$ & 1.02 & 0.932 & 0.65 to 1.60 & 0.97 & 0.887 & $0.60-1.56$ \\
\hline$\geq 8$ & 1.78 & 0.035 & 1.04 to 3.05 & 1.52 & 0.141 & $0.87-2.67$ \\
\hline \multicolumn{7}{|l|}{ Labour market affiliation } \\
\hline Working & 1.00 & - & 1.00 to 1.00 & & & \\
\hline Pensions & 1.43 & 0.434 & 0.58 to 3.49 & & & \\
\hline Out of workforce & 0.72 & 0.294 & 0.39 to 1.33 & & & \\
\hline \multicolumn{7}{|c|}{ Equivalence-weighted disposable income } \\
\hline Low (first quartile) & 1.00 & - & 1.00 to 1.00 & & & \\
\hline Middle (second and third quartile) & 1.32 & 0.288 & 0.79 to 2.19 & & & \\
\hline High (fourth quartile) & 1.35 & 0.299 & 0.77 to 2.35 & & & \\
\hline \multicolumn{7}{|l|}{ Ethnicity } \\
\hline Danish & 1.00 & - & 1.00 to 1.00 & & & \\
\hline Immigrants & 0.95 & 0.885 & 0.46 to 1.95 & & & \\
\hline Descendants of immigrants & 2.59 & 0.344 & 0.36 to 18.55 & & & \\
\hline \multicolumn{7}{|l|}{ Marital status } \\
\hline Single & 1.00 & - & 1.00 to 1.00 & & & \\
\hline Married/living together & 1.06 & 0.783 & 0.71 to 1.58 & & & \\
\hline \multicolumn{7}{|l|}{ Educational level } \\
\hline Low (<10years) & 1.00 & - & 1.00 to 1.00 & 1.00 & - & $1.00-1.00$ \\
\hline Middle (10-12 years) & 1.32 & 0.359 & 0.73 to 2.39 & 1.54 & 0.170 & $0.83-2.87$ \\
\hline High (>12 years) & 2.01 & 0.023 & 1.10 to 3.67 & 2.23 & 0.012 & $1.19-4.19$ \\
\hline
\end{tabular}

${ }^{*}$ Adjusted for age, alcohol consumption and educational level.

Bold denotes significant result with $p$-value $<0.05$.

BMI, body mass index; GP, general practitioner.

and BMI) are self-reported and may be under-reported, thus prone to information bias. However, it has been demonstrated that self-reported anthropometric data are reliable-especially among young people..$^{36}$

\section{Comparison with existing literature}

It has been demonstrated that women lack knowledge about symptoms of gynaecological cancer and that they often attribute the symptoms to benign conditions, ${ }^{38}$ 
increasing age and simply being a woman. ${ }^{39}$ In hypothetical situations of experiencing gynaecological cancer alarm symptoms, many women hesitate to seek medical attention. ${ }^{40}$ Our study confirms that this is also the case when actually experiencing gynaecological alarm symptoms in real life.

Few studies have investigated the associations between healthcare seeking and lifestyle and sociodemography of individuals reporting gynaecological alarm symptoms. In a survey by Brain et al, higher educational level was significantly associated with delay for women in the hypothetical situation of experiencing gynaecological alarm symptoms. ${ }^{40}$ The different results in our study may be due to the fact that Brain et al explore a hypothetical situation with rather vague symptoms, compared with our study with truly experienced symptoms that are more specific of nature. In a study by Elliott $e t a l^{41}$, higher educational level was associated with higher degree of consulting the GP with both low-impact and high-impact symptoms, the tendency being more profound for high-impact symptoms. This supports our findings indicating that higher educational level is indeed positively associated with healthcare-seeking behaviour with gynaecological alarm symptoms of certain impact, as we only found the association for bleeding during intercourse and postmenopausal bleeding.

Another study based on the DaSC-survey has demonstrated that healthcare seeking with respiratory symptoms is significantly lower among smokers. ${ }^{42}$ This may be caused by the well-known association between smoking and respiratory symptoms, which may induce normalisation of, for example, coughing among smokers. Likewise, smokers may experience other barriers towards healthcare seeking such as fear of being blamed for their health conditions being caused by lifestyle. In our study, we did not find such an association, which may indicate that the association between lifestyle and healthcare seeking is specific for the symptoms in question and not generalisable to overall healthcare seeking.

\section{Interpretation of findings}

We evaluated whether social inequity existed with regard to GP contact with gynaecological alarm symptoms, and whether lifestyle influenced the healthcare-seeking process. In the Danish healthcare system, GPs act as gatekeepers and healthcare coordinators for their patients. A prerequisite for further investigations is, however, that patients seek healthcare when experiencing symptoms. We have demonstrated that healthcare seeking with gynaecological cancer alarm symptoms is positively associated with age, ethnicity and educational level. As the risk of cancer increases with age for both endometrial and ovarian cancer, higher proportions of healthcare seeking in the older age groups may be beneficial for detecting these cancers. On the other hand, cervical cancer is also frequently occurring among younger women, and means to promote more appropriate healthcare seeking in the younger age groups must be explored, especially taking into consideration that adherence to cervical screening is lower among younger women. ${ }^{43}$ This study found that higher educational level was positively associated with increased healthcare seeking, while no significant associations were found for lifestyle factors. This might indicate that educational level is a proxy for health literacy, and that the latter is the determining factor for healthcare-related actions rather than lifestyle. In a previous study, we found that higher educational level was positively associated with specialist investigation of gynaecological symptoms. ${ }^{44}$ When taking the results of the present study into account, the social inequality in healthcare utilisation may be even more profound than previously expected. As we found no associations with lifestyle factors, a central point of interest for researchers, clinicians and policy-makers should be the influence of sociodemographic factors on timely diagnosis of symptomatic individuals. At the same time, it must be kept in mind that most of the symptoms are attributable to benign and often normal conditions which poses a challenge for both clinicians, the healthcare system and the symptomatic women who may be exposed to extensive investigations with the risk of iatrogenic harm and psychological distress.

\section{CONCLUSION}

Less than one-third of women contact their GP with newly onset gynaecological cancer alarm symptoms. Higher age, being immigrant and a higher educational level increased the odds of GP contact. Especially the effect of educational level may contribute to social inequality in healthcare utilisation. Future studies should explore the reasons for these findings, and in the meanwhile, clinicians should be aware of patients at risk of not seeking help with symptoms, for example, younger women or women with lower education.

Acknowledgements The Danish Symptom Cohort is conducted in collaboration between University of Southern Denmark and Aarhus University, and the project is imbedded in the research portfolio at the Research Centre for Cancer Diagnosis in Primary Care (CaP). The questionnaire, on which the study is based, was developed in collaboration with Rikke Pilsgaard Svendsen, Anette Fischer Pedersen, Rikke Sand Andersen and Peter Vedsted. The authors thank Maria Munch Storsveen for statistical aid and Merete Moll Lund for proofreading the manuscript.

Contributors KB, SE, SR and DEJ participated in the design of the study, development of the questionnaire, the logistics concerning the survey and the drafting of the manuscript. KB moreover did the main work in forming the manuscript and carried out the statistical analyses. JS participated in the design of the study, development of the questionnaire and drafting of the manuscript. RdC participated in the statistical considerations concerning the survey and analyses. $\mathrm{PFH}$ participated in the interpretation of the findings and drafting of the manuscript. All authors read and approved the final manuscript.

Funding The study is financially supported by the Region of Southern Denmark, the Novo Nordisk Foundation and the Danish Cancer Society.

Competing interests None declared.

Patient consent Not required.

Ethics approval The project was approved by the Danish Data Protection Agency (journal no. 2011-41-6651).

Provenance and peer review Not commissioned; externally peer reviewed. 
Data sharing statement The datasets generated and analysed during the current study are not publicly available due to the data protection regulations of the Danish Data Protection, Statistics Denmark and the Danish Health and Medicines Authority. Access to data is strictly limited to the researchers who have obtained permission for data processing. This permission was granted to the Research Unit of General Practice, Department of Public Health, University of Southern Denmark.

Open access This is an open access article distributed in accordance with the Creative Commons Attribution Non Commercial (CC BY-NC 4.0) license, which permits others to distribute, remix, adapt, build upon this work non-commercially, and license their derivative works on different terms, provided the original work is properly cited and the use is non-commercial. See: http://creativecommons.org/ licenses/by-nc/4.0/

(c) Article author(s) (or their employer(s) unless otherwise stated in the text of the article) 2018. All rights reserved. No commercial use is permitted unless otherwise expressly granted.

\section{REFERENCES}

1. Coleman MP, Forman D, Bryant $\mathrm{H}$, et al. Cancer survival in Australia, Canada, Denmark, Norway, Sweden, and the UK, 1995-2007 (the International Cancer Benchmarking Partnership): an analysis of population-based cancer registry data. Lancet 2011;377:127-38.

2. Neal RD, Tharmanathan P, France B, et al. Is increased time to diagnosis and treatment in symptomatic cancer associated with poorer outcomes? Systematic review. Br J Cancer 2015;112(Suppl 1):S92-107.

3. Maringe C, Walters S, Butler J, et al. Stage at diagnosis and ovarian cancer survival: evidence from the International Cancer Benchmarking Partnership. Gynecol Oncol 2012;127:75-82.

4. Hamilton W. Five misconceptions in cancer diagnosis. Br J Gen Pract 2009;59:441-7.

5. Weller D, Vedsted P, Rubin G, et al. The Aarhus statement: improving design and reporting of studies on early cancer diagnosis. $\mathrm{Br} J$ Cancer 2012;106:1262-7.

6. The Danish National Board of Health. National cancer plan II. Version: 1.0. Copenhagen: National Board of Health, 2005.

7. National Institute for Health and Clinical Excellence. Suspected cancer: recognition and referral 2015. 2017 https://www.nice.org.uk/ guidance/ng12

8. Rasmussen S, Haastrup PF, Balasubramaniam K, et al. Predictive values of upper gastrointestinal cancer alarm symptoms in the general population: a nationwide cohort study. BMC Cancer 2018;18:440.

9. Rasmussen S, Larsen PV, Søndergaard J, et al. Specific and nonspecific symptoms of colorectal cancer and contact to general practice. Fam Pract 2015;32:cmv032-94

10. Rasmussen S, Larsen PV, Svendsen RP, et al. Alarm symptoms of upper gastrointestinal cancer and contact to general practice--A population-based study. Scand J Gastroenterol 2015;50:1268-75.

11. Elnegaard S, Andersen RS, Pedersen AF, et al. Self-reported symptoms and healthcare seeking in the general population-exploring "The Symptom Iceberg". BMC Public Health 2015;15:685.

12. Svendsen RP, Jarbol DE, Larsen PV, et al. Associations between health care seeking and socioeconomic and demographic determinants among people reporting alarm symptoms of cancer: a population-based cross-sectional study. Fam Pract 2013;30:655-65.

13. Salika T, Lyratzopoulos G, Whitaker KL, et al. Do comorbidities influence help-seeking for cancer alarm symptoms? A populationbased survey in England. J Public Health 2017:1-10.

14. Tromp DM, Brouha XD, De Leeuw JR, et al. Psychological factors and patient delay in patients with head and neck cancer. Eur $J$ Cancer 2004;40:1509-16.

15. Tod AM, Craven J, Allmark P. Diagnostic delay in lung cancer: a qualitative study. J Adv Nurs 2008;61:336-43.

16. Chatwin J, Sanders C. The influence of social factors on help-seeking for people with lung cancer. Eur J Cancer Care 2013;22:709-13.

17. Hansen RP, Olesen F, Sørensen HT, et al. Socioeconomic patient characteristics predict delay in cancer diagnosis: a Danish cohort study. BMC Health Serv Res 2008:8:49.

18. Innos K, Padrik P, Valvere V, et al. Identifying women at risk for delayed presentation of breast cancer: a cross-sectional study in Estonia. BMC Public Health 2013;13:947.

19. Brouha X, Tromp D, Hordijk GJ, et al. Role of alcohol and smoking in diagnostic delay of head and neck cancer patients. Acta Otolaryngol 2005;125:552-6.
20. Robinson KM, Christensen KB, Ottesen B, et al. Socio-demographic factors, comorbidity and diagnostic delay among women diagnosed with cervical, endometrial or ovarian cancer. Eur J Cancer Care 2011;20:653-61.

21. Rasmussen S, Søndergaard J, Larsen PV, et al. The Danish symptom cohort: questionnaire and feasibility in the nationwide study on symptom experience and healthcare-seeking among 100000 individuals. Int J Family Med 2014;2014:1-10.

22. Pedersen KM, Andersen JS, Søndergaard J. General practice and primary health care in Denmark. J Am Board Fam Med 2012;25(Suppl 1):S34-38.

23. SurveyXact [program]. 2012.

24. The Danish National Board of Health. Pakkeforløb for kræft $i$ æggestokkene [Cancer package for ovarian cancer]. Version: 3.0. Copenhagen: The Danish National Board of Health, 2011. Versionsdato: 27. juni 2012.

25. The Danish National Board of Health. Pakkeforløb for livmoderhalskræft [Cancer package for cervical cancer]. Version: 3.0. Copenhagen: The Danish National Board of Health, 2012. Versionsdato: 27. juni 2012.

26. The Danish National Board of Health. Pakkeforløb for kræft $i$ livmoderen [Cancer package for endometrial cancer]. Version: 3.0. Copenhagen: National Board of Health, 2012. Versionsdato: 27. juni 2012.

27. National Institute for Health and Clinical Excellence. The recognition and initial management of ovarian cancer. London: NICE, 2011.

28. National Institute for Health and Clinical Excellence. Referral guidelines for suspected cancer. London: NICE, 2005.

29. Thygesen LC, Daasnes C, Thaulow I, et al. Introduction to Danish (nationwide) registers on health and social issues: Structure, access, legislation, and archiving. Scand J Public Health 2011;39(Suppl):12-16.

30. Physical status: the use and interpretation of anthropometry. Report of a WHO Expert Committee. World Health Organ Tech Rep Ser 1995;854:1-452.

31. Jensen VM, Rasmussen AW. Danish registers on personal income and transfer payments. Scand J Public Health 2011;39(Suppl):91-4.

32. Baadsgaard M, Quitzau J. Danish registers on personal income and transfer payments. Scand J Public Health 2011;39(Suppl):103-5.

33. Balasubramaniam K, Ravn P, Larsen PV, et al. Specific and unspecific gynecological alarm symptoms--prevalence estimates in different age groups: a population-based study. Acta Obstet Gynecol Scand 2015;94:191-7.

34. NORDCAN. The NORDCAN project. $2015 \mathrm{http}: / / \mathrm{www}$-dep.iarc.fr/ NORDCAN/English/frame.asp (accessed 20 Sep 2015).

35. Elnegaard S, Pedersen AF, Sand Andersen R, et al. What triggers healthcare-seeking behaviour when experiencing a symptom? Results from a population-based survey. BJGP Open 2017;1.

36. Kuczmarski MF, Kuczmarski RJ, Najjar M. Effects of age on validity of self-reported height, weight, and body mass index: findings from the Third National Health and Nutrition Examination Survey, 1988-1994. J Am Diet Assoc 2001;101:28--34.

37. Nikolaou CK, Hankey CR, Lean MEJ. Accuracy of on-line selfreported weights and heights by young adults. Eur J Public Health 2017;27:898-903.

38. Cooper CP, Polonec L, Stewart SL, et al. Gynaecologic cancer symptom awareness, concern and care seeking among US women: a multi-site qualitative study. Fam Pract 2013;30:96-104.

39. Low EL, Whitaker KL, Simon AE, et al. Women's interpretation of and responses to potential gynaecological cancer symptoms: a qualitative interview study. BMJ Open 2015;5:e008082.

40. Brain KE, Smits S, Simon AE, et al. Ovarian cancer symptom awareness and anticipated delayed presentation in a population sample. BMC Cancer 2014;14:171.

41. Elliott $A M$, McAteer A, Hannaford PC. Incongruous consultation behaviour: results from a UK-wide population survey. BMC Fam Pract 2012;13:21.

42. Sele LM, Elnegaard S, Balasubramaniam K, et al. Lifestyle factors and contact to general practice with respiratory alarm symptoms-a population-based study. BMC Fam Pract 2016;17:47.

43. Willoughby BJ, Faulkner K, Stamp EC, et al. A descriptive study of the decline in cervical screening coverage rates in the North East and Yorkshire and the Humber Regions of the UK from 1995 to 2005. J Public Health 2006;28:355-60.

44. Balasubramaniam K, Ravn P, Christensen RD, et al. Gynecological cancer alarm symptoms: is contact with specialist care associated with lifestyle and socioeconomic status? A population-based study. Acta Obstet Gynecol Scand 2016;95:976-83. 